\title{
Simultaneous adsorption study of ammonium and phosphate by ZnFe-layered double hydroxide (ZnFe- LDH)-modified adsorbents.
}

Feng Liu

Zhejiang University

XINQIANG LIANG ( $\square$ liang410@zju.edu.cn )

Zhejiang University https://orcid.org/0000-0002-3521-9761

Hua Li

Zhejiang Academy of Agricultural Sciences

Yingbing Jin

Zhejiang University

Chuxuan Zhang

Zhejiang University

\section{Ziwan Wang}

Zhejiang University

Guangming Tian

zhejiang university

\section{Research}

Keywords: ZnFe-LDH-modified adsorbent, ceramsite, volcanic rock, ammonium, phosphate, simultaneous adsorption

Posted Date: January 3rd, 2020

DOI: https://doi.org/10.21203/rs.2.19990/v1

License: (c) (1) This work is licensed under a Creative Commons Attribution 4.0 International License. Read Full License 


\section{Abstract}

\section{Background}

Trace amounts of nitrogen and phosphorus can easily trigger eutrophication damage in surface water, while cost-effective adsorption treatment is in prospect for clearing these pollutants simultaneously and efficiently. In this study, engineered adsorbents decorated with ZnFe-LDH by alkaline coprecipitation (3-6 $\mathrm{mm}$, with modified ceramsite as CZF and modified volcanic rock as VZF) were prepared for $\mathrm{NH} 4+$ and $\mathrm{H}$ 2 PO 4 - co-adsorption from aqueous solutions.

Results

Coexisting ions showed great effects on phosphate adsorption, especially $\mathrm{Ca} 2+$ and $\mathrm{CO} 32-$, and humic acid exhibited only a limited shielding impact on co-adsorption properties. Though comprehensive tests presented that the maximum captured amount of ammonium and phosphate occurred at $\mathrm{pH} 7$, the isotherm and kinetic results suggest that two adsorbents preferentially adsorbed each pollutant. Specifically, the maximum uptake quantity of $\mathrm{NH} 4+(15.55 \mathrm{mg}-\mathrm{N} \mathrm{g} \mathrm{-1})$ and $\mathrm{H} 2 \mathrm{PO} 4-(11.21 \mathrm{mg}-\mathrm{P} \mathrm{g}-1)$ were achieved by VZF and CZF, respectively, and controlled by physisorption and chemisorption distinctively, revealing that contaminants were cleared in disparate ways. Performances of seven consecutive adsorption/desorption cycles using $5 \% \mathrm{NaOH}$ regenerant suggested that $\mathrm{CZF}$ retained $71.9 \%$ of PO 4 - removal efficiency, and VZF retained $47.9 \%$ of the $\mathrm{NH} 4+$ adsorption rate, implying the strong reusability of ZnFe-LDH-modified adsorbents. A dynamic study has assessed that with $1 \mathrm{~kg}$ of combined modified adsorbents, approximately $527 \mathrm{~L}$ of polluted runoff flow could be continuously treated to below the National limits within one adsorption cycle.

Conclusion

Comparing with other parallel adsorbents, ZnFe-LDH-modified adsorbent is promising in eliminating eutrophication due to their superior capacity, stability, renewability, and non-toxicity.

\section{Background}

Eutrophication of aquatic systems is commonly caused by the unregulated discharge of agricultural irrigation water and domestic sewage that rich in nitrogen and phosphorus. Generally, their superfluous presence beyond threshold values in surface runoffs will mark stimulatory impacts on non-point eutrophication (above $2 \mathrm{mg} \mathrm{L}^{-1}$ for ammonium $\left(\mathrm{NH}_{4}-\mathrm{N}\right.$ ) and $0.4 \mathrm{mg} \mathrm{L}^{-1}$ for phosphorus (TP)) [1]. As a country dominated by the agricultural industry, China is in large uses of fertilizer containing nitrogen and phosphorus, posing a heavy burden in surface water regulation. Prevalent treatment approaches involve struvite generation [2], biofilm [3], biodegradation [4], and reverse osmosis [5], etc. However, their synchronous removal of ammonium and phosphorus at low concentrations is physically or technically limited in treating non-point polluted cases [6]. 
In tackling this issue, adsorption treatment has been developed as a sustainable and versatile technique that can be employed in real runoff depollution $[7,8]$. Recently, various porous materials have becoming extensively investigated in co-adsorption of ammonium and phosphorus due to their wide availability, facile fabrications, and serving as sorbents by themselves, such as biochar [2, 9], wheat straw [10], clinoptilolite [11, 12], diatomite [13], and red mud [14]. Through proper metal-functionalization, their efficiency, selectivity, and reusability have been promoted considerably compared with pristine filter materials. Among diverse modifications, iron-decoration is regarded as the most promising one due to its high adsorption capacity and environmental friendliness $[15,16]$.

Layered double hydroxides (LDHs) are positively charged materials structured as ordered octahedron and composed of metal hydroxides with anions and water molecules intercalated for charge balance [17]. In its typical expression $\left[\mathrm{N}^{2+}{ }_{(1-x)} \mathrm{N}^{3+}{ }_{x}(\mathrm{OH})_{2}\right]^{\mathrm{x}+}\left[\mathrm{A}^{\mathrm{n}-}\right]_{\mathrm{x} / \mathrm{n}} \cdot \mathrm{mH}_{2} \mathrm{O}, \mathrm{N}^{2+}$ and $\mathrm{N}^{3+}$ serve as bivalent and trivalent metal ions, respectively, and $A^{n-}$ are exchangeable anions [18]. The symbol $x$ describing the metal ratio $(x$ $\left.=\mathrm{N}^{3+} /\left(\mathrm{N}^{2+}+\mathrm{N}^{3+}\right)\right)$ is mainly in the range of $0.2-0.33[19]$. The stunning affinity to phosphate due to the weak interlayer bonding makes LDHs a promising adsorbent in wastewater purification [20-22].

Researchers have proved that $\mathrm{ZnFe}(\mathrm{III})$-based oxides/hydroxides own tremendous capacity for oxyanions scavenge [23-26]. Also, a screening study proposed that $\mathrm{Cl}^{-}$as the exchangeable anions better benefited the LDH adsorption performance than other intercalated substances [27]. Therefore, $\mathrm{ZnFe}$ (III)-Cl-LDH stands out to be the most favorable metal precursor for porous adsorbent functionalization.

Given these backgrounds, the current study aims to: (1) compare the co-adsorption performance and preferential adsorption of ZnFe-LDH-modified adsorbents in terms of adsorption isotherms and kinetics; (2) investigate the effects of interfering ions and organics, and $\mathrm{pH}$ on co-adsorption of ammonium $\left(\mathrm{NH}_{4}^{-}\right.$ $\mathrm{N})$ and phosphorus $\left(\mathrm{PO}_{4}-\mathrm{P}\right)$; (3) assess their sustainability and feasibility in eliminating eutrophication. Due to the prevalent use for water purification, porous matrices including ceramsite and volcanic rock were applied in this work as LDH-nanoparticle carriers. Combining spectroscopic techniques is expected to unravel the co-adsorption mechanisms of modified adsorbents.

\section{Materials And Methods}

\section{Employed materials and adsorbent preparations}

Analytical grade $\mathrm{NH}_{4} \mathrm{Cl}, \mathrm{KH}_{2} \mathrm{PO}_{4}, \mathrm{HCl}, \mathrm{NaOH}, \mathrm{FeCl}_{3} \cdot 6 \mathrm{H}_{2} \mathrm{O}, \mathrm{ZnCl}_{2}, \mathrm{CaCl}_{2}, \mathrm{NaCl}, \mathrm{MgCl}_{2}, \mathrm{KNO}_{3}, \mathrm{~K}_{2} \mathrm{SO}_{4}, \mathrm{~K}_{2} \mathrm{CO}_{3}$, and humic acid (HA) were acquired from Macklin, Shanghai. Natural ceramsite (sphere, 3-6 $\mathrm{mm}$ ) and volcanic rock (irregular shape, 3-6 mm) were commercially procured from Huixiang Co. Ltd, Anhui Province, China.

ZnFe-LDH-modified adsorbents were prepared following an established alkaline coprecipitation method [28]: an amount of clean pristine materials were homogeneously mixed with a $500 \mathrm{~mL}$ aqueous mixture of $\mathrm{FeCl}_{3} \cdot 6 \mathrm{H}_{2} \mathrm{O}$ and $\mathrm{ZnCl}_{2}(\mathrm{Zn}: \mathrm{Fe}=2: 1)$ in a $1 \mathrm{~L}$ beaker. To the solution was dropwise added $5 \mathrm{M} \mathrm{NaOH}$ to 
stabilize the $\mathrm{pH}$ at $11-12$ with vigorous stirring for $4 \mathrm{~h}$ at $85^{\circ} \mathrm{C}$. After thorough precipitation, the solid phases were separated and rinsed to neutral $\mathrm{pH}$ with Milli-Q water, and thereafter oven-dried at $60^{\circ} \mathrm{C}$ for $16 \mathrm{~h}$. Digital photos of modified adsorbents in Fig. S1 didn't show an obvious loss in the resultant size but conspicuous changes in outlook.

\section{Adsorption experimental section}

Batch adsorption experiments were following the pattern unless being specifically stated: in $150 \mathrm{~mL}$ flasks with $100 \mathrm{~mL}$ liquor and adsorbent dosage of $20 \mathrm{~g} \mathrm{~L}^{-1}$ contained, reactions were carried out at $120 \mathrm{rpm}, \mathrm{pH}_{\text {initial }}=7$, and $25 \pm 1^{\circ} \mathrm{C}$ for $48 \mathrm{~h}$ using a thermostatic shaker to ensure equilibrium. The liquor was sampled consecutively at certain intervals. The batch experiments were undertaken in duplicate with mean values of experimental data reported.

The kinetics study was investigated in N-P-binary solutions at concentrations of $50 \mathrm{mg} \mathrm{N} \mathrm{L}^{-1}$ and $10 \mathrm{mg}$ $\mathrm{PL}^{-1}$. According to the timeframe for equilibrium, the optimal timespan was $24 \mathrm{~h}$ and was fixed for the following experiments. Then isotherms adsorption was conducted in unary solutions of ammonium or phosphate within an intensity range of $5-600 \mathrm{mg} \mathrm{L}^{-1}$.

The effects of coexisting ions on co-adsorption were explored in N-P-binary solutions at $30 \mathrm{mg} \mathrm{L}^{-1}$ concentrations, with interfering ions $\left(\mathrm{Ca}^{2+}, \mathrm{Na}^{+}, \mathrm{Mg}^{2+}, \mathrm{NO}_{3}{ }^{-}, \mathrm{SO}_{4}{ }^{2-}\right.$, and $\left.\mathrm{CO}_{3}{ }^{2-}\right)$ individually spiked at an intensity of $1 \mathrm{mM}$. The effect of humic acid was investigated in a density range of $0-80 \mathrm{mg} \mathrm{TOC} \mathrm{L}^{-1}$ in $\mathrm{N}$-P-binary systems at $20 \mathrm{mg}^{-\mathrm{N} \mathrm{L}^{-1}}$ and $10 \mathrm{mg}^{-\mathrm{P} \mathrm{L}^{-1}}$ concentration. Additionally, the impact of $\mathrm{pH}$ on coadsorption was explored in the same system without $\mathrm{HA}$, and in a $\mathrm{pH}$ range of $3-10$. The aqueous $\mathrm{pH}$ gradients were adjusted by $0.1 \mathrm{M} \mathrm{HCl} / \mathrm{NaOH}$. Liquid samples taken from different $\mathrm{pH}$ values after equilibrium were employed for $\mathrm{Zn}$ and Fe measurement after filtration through $0.45 \mu \mathrm{m}$ filters.

\section{Evaluations in reusability and continuous flow adsorption}

The reusability of adsorbents was assessed on the exhausted adsorbents collected from the $\mathrm{pH}$ investigation system $(\mathrm{pH}=7)$. The pollutants-loaded adsorbents were fully rinsed with Milli-Q water to clear away any weakly attached pollutants. Based on the negative performance of adsorbents showed in alkaline media and the exchangeability of sodium hydroxide proposed in a previous paper [29], regeneration was conducted using $5 \mathrm{w} / \mathrm{v} \% \mathrm{NaOH}(\mathrm{pH}=13)$ and thoroughly extracted for $12 \mathrm{~h}$ at $25^{\circ} \mathrm{C}$. After desorption, the solid phases were completely rinsed with Milli-Q water and oven-dried for $4 \mathrm{~h}$ before reuse.

The feasibility evaluation of combined ZnFe-LDH-modified adsorbents for surface wastewater depollution was conducted in a polymethyl methacrylate (PMMA) column $(3.0 \mathrm{~cm}$ diameter and $30 \mathrm{~cm}$ length) packed with $170 \mathrm{~mL}$ of combined modified adsorbents $(1: 1 \mathrm{w} / \mathrm{w})$, where VZF was stacked upon CZF. The eutrophic surface water sample with low pollutant concentrations $\left(2.0 \mathrm{mg}-\mathrm{N} \mathrm{L}^{-1}, 0.46 \mathrm{mg}-\mathrm{P} \mathrm{L}^{-}\right.$

$\left.{ }^{1}\right)$ was collected from Changxing County $\left(119^{\circ} 93^{\prime} \mathrm{E}, 30^{\circ} 93^{\prime} \mathrm{N}\right)$, Zhejiang Province, China, and continuously pumped through the column at a $1.8 \mathrm{~mL} \mathrm{~min}^{-1}$ speed (EBCT $=95 \mathrm{~min}$ ). The breakpoints for 
$\mathrm{N}$ and $\mathrm{P}$ in effluent were defined as $1 \mathrm{mg} \mathrm{L}^{-1}\left(\mathrm{NH}_{4}-\mathrm{N}\right)$ and $0.2 \mathrm{mg} \mathrm{L}^{-1}$ (TP) to conform to the China national Class III quality standard for surface water (GB3838-2002). The effluent was collected every $300 \mathrm{~min}$ and targeted pollutants were measured after filtration through glass microfiber filters (Whatman, GF/F).

\section{Analytical methods}

Aqueous ammonium and phosphate concentrations were measured calorimetrically using a UV-visible spectrophotometer (METASH, UV-765PC, China). Liquid pH values were determined by an HQ 11D pH meter ( $\mathrm{HACH}, \mathrm{USA})$. Humic acid concentrations were measured by an automated TOC analyzer (TOC-V, Shimadzu, Japan). Metal contents of solid-phase extracted by $\mathrm{HNO}_{3}-\mathrm{HClO}_{4}$ and metal leaching amounts from various $\mathrm{pH}$ media were quantified by inductive-coupled plasma-optical emission spectrometry (ICPOES, PerkinElmer, USA). Cations and anions were identified and tested via the ion chromatography system (ICS-1100, Dionex, USA). Modified adsorbents were characterized systematically by the following techniques: (1) the surface morphology and elemental analysis were characterized by a scanning electron microscopy (SEM) (SU 8010, Hitachi, Japan) with an energy-dispersive spectrometer (EDS) (Oxford Instruments X-Max); (2) Nitrogen gas $\left(\mathrm{N}_{2}\right)$ adsorption and desorption tests were conducted by an automated adsorption apparatus (MicroActive for TriStar II Plus 2.02, USA); (3) chemical compositions were identified via X-ray fluorescence spectrometer (XRF, Thermo ARL 9900); and (4) chemical states of Zn 2p, Fe 2p, N 1 s and P 2p on adsorbents were distinguished by XPS (ESCALAB 250 Xi, Thermo Scientific, USA). $\mathrm{pH}_{\mathrm{pzc}}$ and CEC measurements of modified adsorbents were described in Supplementary information SI, Section S1-S2.

\section{Statistical analysis}

In this study, uptake capacities and the best-fits to isotherm and kinetic models were calculated with the calculation formulae listed in SI. Section S3, parameters of kinetic and isotherm curves were generated by Auto2Fit software. Experimental data of the influences of interfering ions were statistically analyzed via analysis of variance (ANOVA) by SPSS version 18.0.

\section{Results And Discussion}

\section{Systematic characterizations of modified adsorbents}

SEM analyses for the morphologies of adsorbents before and after ZnFe-LDH-modification are presented in Fig. 1. Dense coating of ZnFe-LDH chips has roughened the surface of CZF (b-c) and VZF (e-f) in comparison with the even outlook of the original ceramsite (a) and volcanic rock (d). Meanwhile, higher porosity and the overlapping texture exhibited on modified adsorbents indicate an upscaled heterogeneity. As shown in Fig. S2, EDS mapping presented the intermittent islands of ZnFe-LDH accumulated as $\left[\mathrm{Zn}_{0.69} \mathrm{Fe}_{0.31}(\mathrm{OH})_{2}\right](\mathrm{Cl})_{0.31} \cdot \mathrm{mH}_{2} \mathrm{O}$ and $\left[\mathrm{Zn}_{0.68} \mathrm{Fe}_{0.32}(\mathrm{OH})_{2}\right](\mathrm{Cl})_{0.32} \cdot \mathrm{mH}_{2} \mathrm{O}$ on CZF and VZF surface, respectively. Particularly, the molar fractions of $\mathrm{Zn}$ and Fe atoms of CZF were distinctly higher than those of VZF. The results of acidic solid-digestion turned out the impregnated ZnFe-LDH contents in 
CZF and VZF were $30.8 \mathrm{mg} \mathrm{g}^{-1}$ and $20.6 \mathrm{mg} \mathrm{g}^{-1}$, respectively, suggesting more LDH-functionality has been embedded into CZF.

The key physicochemical properties of modified adsorbents were listed in Table 1. Notably, CZF (5.3 m² $\left.\mathrm{g}^{-1}\right)$ and VZF $\left(3.7 \mathrm{~m}^{2} \mathrm{~g}^{-1}\right)$ obtained higher specific surface area (SSA) values than their original ones $\left(1.6 \mathrm{~m}^{2} \mathrm{~g}^{-1}\right.$ and $\left.2.5 \mathrm{~m}^{2} \mathrm{~g}^{-1}\right)$, which were benefited from the introduced nanoparticles with high SSA. As shown in Fig. S3, the $\mathrm{N}_{2}$ sorption/desorption isotherms of prepared samples exhibited $\mathrm{H} 3$ hysteresis loops in type IV isotherms, especially VZF, implying the slit-shaped pores of packing plate-like particle and the occurrence of $\mathrm{N}_{2}$ physical adsorption on heterogeneous interfaces [30]. Such an escalation in heterogeneity as also being corroborated by the increased pore volume and pore radius should be ascribed to the built-in modification that provided more porosity and ion exchange channels for targeted adsorbates (Table 1) [31]. Additionally, the suggested $\mathrm{pH}_{\mathrm{pzc}}$ values of CZF (8.90) and VZF (8.79) were substantially elevated compared with the ZnFe-LDH nanoparticle (6.4) [32]. When the liquid $\mathrm{pH}$ is below the proposed $\mathrm{pH}_{\mathrm{pzc}}$, the solid will be positively charged through metal hydroxide protonation (Eq. 1-2). Thus, phosphorus removal will be enhanced by electrostatic attraction due to the charge complementarity [33]. Particularly, VZF was of a greater CEC property, which is in agreement with its higher mass proportion of $\mathrm{Na}^{+}$in the EDS result and higher $\mathrm{Na}^{+}$content that noticed in the chemical composition, and is expected to benefit the $\mathrm{NH}_{4}{ }^{+}$capture. Meanwhile, the remarkable increase in the contents of $\mathrm{Zn}$ and Fe compounds after modification suggests the successful LDH-functionalization. 
Table 1

Physicochemical properties of the natural and ZnFe-LDH-modified adsorbents.

\begin{tabular}{|c|c|c|c|c|}
\hline Parameters & Ceramsite & CZF & Volcanic rock & VZF \\
\hline \multicolumn{5}{|l|}{ Physical properties } \\
\hline Specific surface area $\left(\mathrm{m}^{2} \mathrm{~g}^{-1}\right)$ & 1.55 & 5.25 & 2.50 & 3.65 \\
\hline $\mathrm{pH}_{\mathrm{pzc}}$ & / & 8.90 & / & 8.79 \\
\hline Pore volume $\left(\mathrm{cc} \mathrm{g}^{-1}\right)$ & 0.002 & 0.012 & 0.004 & 0.013 \\
\hline Pore radius $(\mathrm{nm})$ & 6.45 & 7.36 & 5.05 & 8.05 \\
\hline Cation exchange capacity $\left(\mathrm{mmol} \mathrm{g}^{-1}\right)$ & $6.9 \pm 0.1$ & $4.7 \pm 0.1$ & $9.2 \pm 0.1$ & $6.5 \pm 0.1$ \\
\hline \multicolumn{5}{|l|}{ Chemical composition ( $\mathrm{m} / \mathrm{m} \%)$} \\
\hline $\mathrm{Fe}_{2} \mathrm{O}_{3}$ & 1.8 & 13.9 & 1.4 & 9.8 \\
\hline $\mathrm{ZnO}$ & N.D. ${ }^{a}$ & 25.4 & N.D. & 17.8 \\
\hline $\mathrm{Na}_{2} \mathrm{O}$ & 5.0 & 3.4 & 13.0 & 9.3 \\
\hline $\mathrm{K}_{2} \mathrm{O}$ & 3.8 & 2.1 & 5.8 & 3.9 \\
\hline $\mathrm{MgO}$ & 6.4 & 1.5 & 3.5 & 2.7 \\
\hline $\mathrm{CaO}$ & 12.1 & 1.3 & 6.7 & 5.9 \\
\hline $\mathrm{Al}_{2} \mathrm{O}_{3}$ & 24.7 & 19.3 & 24.6 & 16.4 \\
\hline $\mathrm{SiO}_{2}$ & 39.2 & 29.0 & 44.8 & 30.2 \\
\hline Other & 7.0 & 4.1 & 0.2 & 4.0 \\
\hline
\end{tabular}

All of these factors synergistically facilitated the co-adsorption of cationic $\mathrm{NH}_{4}{ }^{+}$and anionic $\mathrm{H}_{2} \mathrm{PO}_{4}{ }^{-}$, despite the reverse charge, onto ZnFe-LDH-modified adsorbents via diverse pathways.

\footnotetext{
$\mathrm{H}_{2} \mathrm{PO}_{4}^{-}+\mathrm{H}_{2} \mathrm{O}+\equiv \mathrm{FeOH} \stackrel{p H<p H_{p z c}}{\longrightarrow} \equiv \mathrm{FeOH}_{2}+\cdots \mathrm{H}_{2} \mathrm{PO}_{4}+\mathrm{OH}^{-}$

$\mathrm{H}_{2} \mathrm{PO}_{4}{ }^{-}+\mathrm{H}_{2} \mathrm{O}+\equiv \mathrm{ZnOH} \stackrel{p H<p H_{p z c}}{\longrightarrow} \equiv \mathrm{ZnOH}_{2}+\cdots \mathrm{H}_{2} \mathrm{PO}_{4} \mid+\mathrm{OH}^{-}$

\section{Comparison of modified adsorbents in kinetics and isotherms studies}


The intake performances of original and modified adsorbents in sole and binary-pollutant media were displayed in Fig. S4. The obvious increments of modified adsorbents in $\mathrm{NH}_{4}{ }^{+}$and $\mathrm{H}_{2} \mathrm{PO}_{4}{ }^{-}$sorption capacities compared with the unmodified suggest that ZnFe-LDH modification has improved the synchronous removal efficiency. Meanwhile, the co-uptake behaviors in binary systems witnessed insignificant fluctuations in contrast to those in sole systems, implying the bifunctionality of modified adsorbents won't weaken during co-adsorption.

Further insights into the co-adsorption processes of modified adsorbents were collected in Fig. S5a. Specifically, the co-adsorption capability of VZF $\left(1.21 \mathrm{mg} \mathrm{g}^{-1}\right)$ was marginally higher than that of CZF $\left(1.18 \mathrm{mg} \mathrm{g}^{-1}\right)$. In comparison, CZF showed a higher equilibrium capability of $0.45 \mathrm{mg}^{-\mathrm{P} \mathrm{g}^{-1}}$ for phosphorus adsorption, and VZF exhibited a greater efficiency of $2.14 \mathrm{mg}-\mathrm{N} \mathrm{g}^{-1}$ for ammonium removal, indicating the preferential adsorption by different adsorbents. The controlling mechanisms of $\mathrm{NH}_{4}{ }^{+}$and $\mathrm{H}_{2} \mathrm{PO}_{4}{ }^{-}$adsorption were clarified by three kinetic models (Table S1). As corroborated by the highest correlation coefficients $\left(R^{2}>0.9\right)$ and the lowest RMSE and SSE values, pseudo-first-order best fitted the ammonium adsorption behavior, and pseudo-second-order better explained the trend of phosphorus removal. Thus, physisorption dominated the $\mathrm{NH}_{4}{ }^{+}$removal, where $\mathrm{NH}_{4}{ }^{+}$was captured by substituting with the intrinsic cations of materials; while $\mathrm{H}_{2} \mathrm{PO}_{4}{ }^{-}$adsorption was prompted by chemisorption, which involves around complexes formation, sharing electrons, and anion intercalation [9].

As the isotherms depicted in Fig. $\mathrm{S} 5 \mathrm{~b}$, sorption capabilities of adsorbents for $\mathrm{NH}_{4}{ }^{+}$and $\mathrm{H}_{2} \mathrm{PO}_{4}{ }^{-}$increased with the increased equilibrium concentrations. By comparing correlation coefficients of three models (Table S1), the $\mathrm{NH}_{4}{ }^{+}$and $\mathrm{H}_{2} \mathrm{PO}_{4}{ }^{-}$adsorption processes were found to follow the Sips isotherm $\left(\mathrm{R}^{2}>0.99\right)$. Accordingly, the maximum adsorption capacities for $\mathrm{NH}_{4}{ }^{+}$and $\mathrm{H}_{2} \mathrm{PO}_{4}{ }^{-}$were calculated by Sips model as $15.55 \mathrm{mg} \mathrm{N} \mathrm{g}^{-1}$ obtained by VZF and $11.21 \mathrm{mg} \mathrm{P} \mathrm{g}^{-1}$ achieved by CZF, revealing that VZF and CZF had their corresponding affinities for ammonium and phosphate, respectively. The highest affinity for targeted contaminants reported by $\mathrm{K}_{\mathrm{f}}$ was deduced from the Freundlich isotherm, whose $\mathrm{n}$ values of all adsorption processes were higher than 1 , demonstrating favorable adsorption performances [33]. Therefore, the multilayer adsorption was dominant during the $\mathrm{NH}_{4}{ }^{+}$and $\mathrm{H}_{2} \mathrm{PO}_{4}{ }^{-}$capture processes. In this study, the maximum sorption capacity of modified adsorbents for synchronous removal of $\mathrm{N}$ and $\mathrm{P}$ was greater than the various adsorbents reported in Table S2, leading to their strong competitiveness.

\section{Mechanisms in simultaneous adsorption}

To unveil the adsorption mechanisms responsible for simultaneous uptake of phosphorus and ammonium by ZnFe-LDH-modified adsorbents, both fresh and pollutants-saturated adsorbents were collected, followed by characterization with XPS. Compared with the ones before pollutants interactions, the full scan of modified adsorbents after adsorption shows the disappearance of the $\mathrm{Cl} 2 \mathrm{p}$ and $\mathrm{Na} 1 \mathrm{~s}$ core peaks, and new P 2p and N 1 s peaks occurred at $134.0 \mathrm{eV}$ and $400.2 \mathrm{eV}$, respectively (Fig. S6a), indicating that ion exchange controlled the $\mathrm{N}$ and $\mathrm{P}$ capture to some extent. As shown in Fig. 2a, two 
peaks at $134.1 \mathrm{eV}$ and $133.7 \mathrm{eV}$ were correlated with the typical $\mathrm{HPO}_{4}{ }^{2-}$ and $\mathrm{H}_{2} \mathrm{PO}_{4}{ }^{-}$[34]. Thus, $\mathrm{P}$ was mainly removed as anions through ion exchange and electrostatic attraction rather than being immobilized by precipitating as $\mathrm{Zn}-\mathrm{PO}_{4}$ or $\mathrm{Fe}^{-} \mathrm{PO}_{4}$. As noted in Fig. $2 \mathrm{~b}$, two peaks at $400.5 \mathrm{eV}$, and $406.8 \mathrm{eV}$ correspond to $\mathrm{NH}_{4}{ }^{+}$in different forms [11], which were retained by exchanging with the inherent $\mathrm{Na}^{+}$, as can be demonstrated by the diminished Na percentages. The $Z \mathrm{n} 2 \mathrm{p}_{3 / 2}$ peak (1022.8 eV) and the $\mathrm{Fe} 2 \mathrm{p}_{3 / 2}(711.3 \mathrm{eV})$ peak with their shakeup satellites before and after adsorption were shown in Fig. S6b [32]. Notably, no shift has occurred to the Zn element; the upward shift in the Fe $2 p$ peak (0.2-1 eV), however, suggests that the fixation of $\mathrm{P}$ can be speculated to form at the ligand shell of Fe atoms. Thus, Fe has a direct affinity for $\mathrm{P}$, while the $\mathrm{Zn}$ atom served as the architecture supporter ensuring the LDH stability upon phosphate interaction [35].

Overall, the mechanisms behind the co-capture of ammonium and phosphate by ZnFe-LDH-modified adsorbents can be elucidated in Fig. 3. Phosphorus adsorption can be mainly ascribed to nonspecific adsorption, namely, the anion exchange between anionic $\mathrm{P}\left(\mathrm{H}_{2} \mathrm{PO}_{4}{ }^{-}\right.$and $\left.\mathrm{HPO}_{4}{ }^{2-}\right)$ and $\mathrm{Cl}^{-}$in the $\mathrm{LDH}$ inner corridor and electrostatic attraction by protonated metal hydroxyl, with a few specific ligand exchanges by forming mono/bidentate complexes. Meanwhile, the cation exchange between $\mathrm{Na}^{+}$and $\mathrm{NH}_{4}{ }^{+}$as described in Eq. 3-4 was responsible for the ammonium uptake. Compared with CZF, the ammonium preference of VZF came from the larger pore radius and higher $\mathrm{Na}^{+}$content of raw materials providing generous cation retention capacities for more $\mathrm{NH}_{4}{ }^{+}$.

$$
\begin{aligned}
& \text { Ceramsite } \cdots \mathrm{Na}^{+}+\mathrm{NH}_{4}{ }^{+} \leftrightarrow \text { Ceramsite } \cdots \mathrm{NH}_{4}{ }^{+}+\mathrm{Na}^{+} \\
& \text {Volcanic rock } \cdots \mathrm{Na}^{+}+\mathrm{NH}_{4}{ }^{+} \leftrightarrow \text { Volcanic rock } \cdots \mathrm{NH}_{4}{ }^{+}+\mathrm{Na}^{+}
\end{aligned}
$$

\section{Influences of coexisting anions, cations, and organics on adsorption}

Many kinds of salts, including cations $\left(\mathrm{Ca}^{2+}, \mathrm{Na}^{+}\right.$, and $\left.\mathrm{Mg}^{2+}\right)$ and anions $\left(\mathrm{NO}_{3}{ }^{-}, \mathrm{SO}_{4}{ }^{2-}\right.$, and $\left.\mathrm{CO}_{3}{ }^{2-}\right)$, are present in real runoffs. However, coexisting ions had various influences on adsorption, and the modified adsorbents exhibited similar responses. As can be noted in Fig. 4 a, no noticeable decrement in $\mathrm{NH}_{4}{ }^{+}$ adsorption was witnessed in the presence of extra ions, except for $\mathrm{NO}_{3}{ }^{-}(\mathrm{p}<0.001)$. Compared with $\mathrm{SO}_{4}{ }^{2-}$ $\left(\Delta \mathrm{G}^{\circ}=-1090 \mathrm{~kJ} \mathrm{~mol}^{-1}\right)$ and $\mathrm{CO}_{3}{ }^{2-}\left(\Delta \mathrm{G}^{\circ}=-368 \mathrm{~kJ} \mathrm{~mol}^{-1}\right), \mathrm{NO}_{3}{ }^{-}$with lower hydration energy $\left(\Delta \mathrm{G}^{\circ}=-306 \mathrm{~kJ}\right.$ $\mathrm{mol}^{-1}$ ) has undergone Lewis acid/base reaction with metal, leading to inner-sphere complexes synthesized on the adsorbent surface that hindered the $\mathrm{NH}_{4}{ }^{+}$diffusion passages into adsorbents[8, 36]. Nonetheless, VZF's stable uptake of $\mathrm{NH}_{4}{ }^{+}$when confronting interfering cations marked its selectivity to $\mathrm{NH}_{4}{ }^{+}$. For phosphorus removal, $\mathrm{Ca}^{2+}$ was the most favorable $(\mathrm{p}<0.001), \mathrm{Mg}^{2+}$ had negligible effects, and the rest of the ions $\left(\mathrm{Na}^{+}, \mathrm{NO}_{3}{ }^{-}, \mathrm{SO}_{4}{ }^{2-}\right.$, and $\left.\mathrm{CO}_{3}{ }^{2-}\right)$ have obvious shielding effects on the amounts of $\mathrm{P}$ 
captured $(p<0.001)$. Ca-P amorphous precipitates with low $\mathrm{K}_{\mathrm{sp}}$ values tend to be intercepted by the host pore structure [37], thus promoting phosphorus removal. It is comprehensible that oxyanions inhibited phosphorus removal by competing for LDH's anion exchange capacity and electrostatic adsorption sites [31]. The dramatic dive in $\mathrm{P}$ ingestion in the presence of $\mathrm{CO}_{3}{ }^{2-}$ was ascribed to carbonate's priority into the $\mathrm{LDH}$ interzone and due to the $\mathrm{OH}^{-}$-induced competitive adsorption resulted from its hydrolysis $\left(\mathrm{k}_{\mathrm{h}}=2.12 \times 10^{-4}\right)$ [38]. Inhibition rendered by background electrolytes $\left(\mathrm{Na}^{+}\right)$can be interpreted by its competition with the electrostatically-adsorbed phosphate on the outer-sphere adsorption sites [39]. Such ions-dependent adsorption indicates that phosphorus removal was mainly attributed to the nonspecific interactions brought about by LDH. In summary, better co-adsorption quantities observed in VZF suggest a more stable performance of VZF when confronting with extraneous salt interference. Despite the truth that coexisting ions engendered heavier effects on phosphate adsorption than ammonium capture, the mechanically sturdy hosts in this study endowed LDH architecture with integrity to reduce much interference, as compared with the ion-sensitivity showed in the previous study [31].

Humic acid (HA) is a typical dissolved organic matter in eutrophic water bodies. However, HA showed shielding effects on $\mathrm{NH}_{4}{ }^{+}$and $\mathrm{H}_{2} \mathrm{PO}_{4}{ }^{-}$co-adsorption in the current practice (Fig. 4b). As the $\mathrm{HA}$ intensity ascended from 2 to $5 \mathrm{mg} \mathrm{L}^{-1}$, a limited loss was engendered in phosphate removal (16-24\% for CZF and $0-1 \%$ for VZF), and no significant change took place afterward. This is consistent with a preceding study [21]. Negatively charged HA reduced specific phosphorus adsorption by forming inner-sphere complexes on the LDH [40]. Therefore, the increase of HA intensity won't further suppress the nonspecific phosphorus adsorption. For ammonium ingestion, the inhibitory effect was slight (3-16\%) when the HA intensity was below $40 \mathrm{mg} \mathrm{L}^{-1}$; after that, however, ammonium removal of VZF descended drastically (47\%). This can be explained that $\mathrm{NH}_{4}{ }^{+}$could electrostatically attach to organics and then remain in solutions [41]; thus, the ammonium abatement was obstructed as HA increased. To sum up, the shielding effect of HA was weaker when capturing phosphate than when holding ammonium. Thanks to the robust phosphorus removal of LDH structure, CZF achieved better co-uptake under dramatic HA interference. Compared with other LDH-adsorbents [42], this work has faced down the issue of HA interference on phosphorus due to the fixing advantage of the host materials. Further investigation of metal leaching in the presence of $\mathrm{HA}$ is required.

\section{Influences of $\mathrm{pH}$ on simultaneous adsorption}

As can be seen in Fig. 5, pH has significant influences on the $\mathrm{NH}_{4}{ }^{+}$and $\mathrm{H}_{2} \mathrm{PO}_{4}{ }^{-}$adsorption of modified adsorbents. In the studied $\mathrm{pH}$ range, both adsorbents exhibited the highest co-adsorption capacities at $\mathrm{pH}$ 7, with the total uptake quantity of $0.67 \mathrm{mg} \mathrm{g}^{-1}$ by CZF and that of $0.73 \mathrm{mg} \mathrm{g}^{-1}$ by VZF. Meanwhile, $\mathrm{NH}_{4}^{+}$ removal efficiencies of both adsorbents crested at $\mathrm{pH} 7$ (29.2\% for CZF, $56.9 \%$ for VZF), and gradually reduced when $\mathrm{pH}$ turned to acidic or alkaline regions. This scene is aligned with the previous finding [43]. In alkaline liquid systems, cationic $\mathrm{NH}_{4}{ }^{+}\left(\mathrm{pK}_{\mathrm{a}}=9.25\right)$ would convert into $\mathrm{NH}_{3}$ (Fig S6a), a non-protonated form that resists cation exchange [44]; while in acidic solutions, the increased concentration of $\mathrm{H}^{+}$would enhance the competition with $\mathrm{NH}_{4}{ }^{+}$, causing suppression on ammonium intake [44]. Additionally, both 
adsorbents worked better in removing phosphate at $\mathrm{pH} 3$ (100.0\% for CZF, $65.0 \%$ for VZF), and VZF shifted its preference from ammonium to phosphate when $\mathrm{pH}<6$. As shown in Fig. S7b, the species of phosphorus in the neutral medium were mainly $\mathrm{H}_{2} \mathrm{PO}_{4}{ }^{-}\left(\mathrm{pK}_{1}=2.15\right)$ and $\mathrm{HPO}_{4}{ }^{2-}\left(\mathrm{pK}_{2}=7.20\right)$, which are favorable for the phosphorus adsorption[8]. Whereas phosphate adsorption in the alkaline region was reduced by the electrostatic repulsion of negatively charged adsorbents when $\mathrm{pH}>\mathrm{pH}_{\mathrm{pzc}}$ and by the adsorption competition between $\mathrm{OH}^{-}$and anionic phosphate [45]. Overall, $\mathrm{pH}$ has heavier influences on the capture process of $\mathrm{NH}_{4}{ }^{+}$than that of $\mathrm{H}_{2} \mathrm{PO}_{4}{ }^{-}$. In contrary to recent research [31], the robust $\mathrm{P}$ intake of $\mathrm{CZF}$ over such a wide $\mathrm{pH}$ range can be attributed to the anti-interference properties that the original host provided. In this way, CZF exhibited better adaptation than VZF under pH fluctuations.

As can be seen in Table S3, the released amount of $\mathrm{Zn}^{2+}(0.0017-0.0089 \mathrm{ppm})$ after adsorption at $\mathrm{pH} 7$ were below the toxic thresholds for aquatic systems $(0.05 \mathrm{ppm})$ and plants $(0.01-0.13 \mathrm{ppm})[1,46]$, and farther beneath the National limits of dangerous wastes (GB 5085.3-2007). Meanwhile, the released $\mathrm{Fe}^{3+}$ was even more negligible. The above results demonstrated that ZnFe-LDH-modified adsorbent could satisfy most natural circumstances.

\section{Regeneration cycles and continuous flow adsorption test}

Considering the ever-increasing calls for the regeneration strategy, seven consecutive adsorption/desorption cycles were performed on current adsorbents via $5 \% \mathrm{NaOH}$ regenerant. As depicted in Fig. 6, all sequential cycles noticed a limited drop in the first two cycles and plateaued from cycle 3. Throughout the cyclic adsorption, CZF and VZF retained robust decontamination efficiency for $\mathrm{H}_{2} \mathrm{PO}_{4}{ }^{-}(71.9 \%)$ and $\mathrm{NH}_{4}{ }^{+}$(47.9\%), respectively, while underperformed in their non-preferential pollutants (12.7\%). Meanwhile, desorption cycles exhibited in Fig. S8 found the constant P desorption performance (>93.0\%), indicating that the nonspecific $\mathrm{P}$ adsorption could be reversed and renewed by abundant hydroxyl ions. The irreversible desorption portion was attributed to specific adsorption that formed strong metal-P bonding. Compared with parallel studies $[47,48]$, the repeated chemical desorption in this study didn't perform significant impair in performance and weight aspects of the modified materials, suggesting their strong reusability in the potential engineering practice.

Figure $6 \mathrm{~b}$ exhibits the breakthrough curve of the column experiment and quality parameters of the collected real wastewater sample. The results demonstrate that modified adsorbents were able to purify continuous wastewater flow. The phosphate removal capacity was $0.16 \mathrm{mg}-\mathrm{P} \mathrm{g}^{-1}$ at a handling capacity of $605 \mathrm{BV}$, which is 4.4 times the Sips result $\left(0.036 \mathrm{mg} \mathrm{g}^{-1}\right)$ at the same treating concentration. Meanwhile, ammonium was constantly well removed to below $0.4 \mathrm{mg} \mathrm{L}^{-1}$, with the scavenging capability of $1.0 \mathrm{mg}-\mathrm{N} \mathrm{g}^{-1}$ acquired at $620 \mathrm{BV}$ was 166.7 folds the Sips result $\left(0.006 \mathrm{mg}-\mathrm{N} \mathrm{g}^{-1}\right)$. It can be inferred that $1 \mathrm{~kg}$ of combined ZnFe-LDH modified adsorbents could process $527 \mathrm{~L}$ of eutrophic runoff flow within one adsorption cycle, corresponding to $9.5 \%$ of dosage employed in the synthetic-based test. Such efficiency implies that modified adsorbents show stable selectivity for ammonium and phosphorus with large-capacity adsorption even under interference. However, considering the porous nature, the modified 
material is more suitable for the purification of eutrophic water with less suspended particles and alkalinity in order to prevent pore blockage. Thanks to the durability, the continued elimination of $\mathrm{N}$ and $\mathrm{P}$ will offset the fabrication cost from a long-term perspective, making the adsorbent a cost-effective choice. Further studies on fixed-column optimization and lifespan predictions are warranted.

\section{Conclusions}

Here, ZnFe-LDH-decorated adsorbents based on ceramsite and volcanic rock were prepared for the simultaneous removal of ammonium and phosphorus. Despite superior adsorption capacities in comparison with various adsorbents, CZF and VZF showed the corresponding affinity for $\mathrm{H}_{2} \mathrm{PO}_{4}^{-}$ (11.21 mg-P g $\left.{ }^{-1}\right)$ and $\mathrm{NH}_{4}{ }^{+}\left(15.55 \mathrm{mg}-\mathrm{N} \mathrm{g}^{-1}\right)$, respectively. Among studied influencing factors, coexisting ions $\left(\mathrm{Ca}^{2+}\right.$ and $\left.\mathrm{CO}_{3}{ }^{2-}\right)$ have greater effects on phosphate adsorption, while $\mathrm{pH}$ and humic acid interfered more with ammonium adsorption. Correspondingly, CZF behaved better in most scenarios. The XPS analysis proved that ammonium was mainly removed by the cation exchange of raw materials, while phosphorus was taken up by the coated LDH through anion intercalation, electrostatic attraction, and ligand exchange, thus the two occupied distinct ways during co-purification. Overall, due to the low metal leaching, renewability, and practicality in dynamic flow indicate that the ZnFe-LDH-modified adsorbent is a promising candidate for eutrophication mitigation.

\section{Abbreviations}

P:phosphorus; N:ammonium; LDH:layered double hydroxide; CZF:modified ceramsite; VZF:modified volcanic rock; HA:humic acid; ICP-OES:inductive-coupled plasma-optical emission spectrometry; SEM:scanning electron microscopy; EDS:energy-dispersive spectrometer; ICS:ion chromatography system; XRF:X-ray fluorescence spectrometer; and CEC:cation exchange capacity.

\section{Declarations}

\section{Ethics approval and consent to participate}

Not applicable.

\section{Consent for publication}

Not applicable.

\section{Availability of data and materials}

Not applicable.

\section{Competing interests}

The authors declare that they have no competing interests. 


\section{Funding}

The authors appreciate supports from the National Key Science and Technology Project: Water Pollution Control and Treatment [grant number 2018ZX07208009]; National Key Research and Development Program of China [grant number 2017YFD0800103]; National Natural Science Foundation of China [grant number 41671300]; and Natural Science Foundation of Zhejiang Province [grant number LR16B070001].

\section{Author's contributions}

FL accomplished experiments and manuscript, $\mathrm{XL}$ is the corresponding author, $\mathrm{HL}, \mathrm{YB}, \mathrm{CZ}, \mathrm{ZW}$, and $\mathrm{GT}$ designed, participated and were involved in revising the manuscript. All authors read and approved the final manuscript.

\section{Acknowledgements}

We highly appreciate everyone who contributed to accomplish this study.

\section{References}

1. Su J, Ji D, Lin M, et al (2017) Developing surface water quality standards in China. Resour Conserv Recycl 117:294-303.

2. Xu K, Lin F, Dou X, et al (2018) Recovery of ammonium and phosphate from urine as value-added fertilizer using wood waste biochar loaded with magnesium oxides. J Clean Prod 187:205-214.

3. Leyva-Díaz JC, Monteoliva A, Martín-Pascual J, et al (2019) Moving bed biofilm reactor as an alternative wastewater treatment process for nutrient removal and recovery in the circular economy model. Bioresour Technol 122631.

4. Ma H, Zhang Y, Xue Y, Li Y-Y (2018) A new process for simultaneous nitrogen removal and phosphorus recovery using an anammox expanded bed reactor. Bioresour Technol 267:201-208.

5. Tian X, Wang G, Guan D, et al (2016) Reverse osmosis brine for phosphorus recovery from source separated urine. Chemosphere 165:202-210.

6. Wei SP, van Rossum F, van de Pol GJ, Winkler M-KH (2018) Recovery of phosphorus and nitrogen from human urine by struvite precipitation, air stripping and acid scrubbing: A pilot study. Chemosphere 212:1030-1037.

7. Bacelo H, Pintor AMA, Santos SCR, et al (2020) Performance and prospects of different adsorbents for phosphorus uptake and recovery from water. Chem Eng J 381:122566.

8. Wu B, Wan J, Zhang Y, et al (2019) Selective Phosphate Removal from Water and Wastewater using Sorption: Process Fundamentals and Removal Mechanisms. Environ Sci Technol.

9. Yin Q, Wang R, Zhao Z (2018) Application of Mg-Al-modified biochar for simultaneous removal of ammonium, nitrate, and phosphate from eutrophic water. J Clean Prod 176:230-240. 
10. Wang X, Lü S, Gao C, et al (2016) Recovery of Ammonium and Phosphate from Wastewater by Wheat Straw-based Amphoteric Adsorbent and Reusing as a Multifunctional Slow-Release Compound Fertilizer. ACS Sustain Chem Eng 4:2068-2079.

11. Zhou K, Wu B, Dai X, Chai X (2018) Development of polymeric iron/zirconium-pillared clinoptilolite for simultaneous removal of multiple inorganic contaminants from wastewater. Chem Eng $\mathrm{J}$ 347:819-827.

12. Xu Q, Li W, Ma L, et al (2020) Simultaneous removal of ammonia and phosphate using green synthesized iron oxide nanoparticles dispersed onto zeolite. Sci Total Environ 703:135002.

13. Li J, Wang X, Wang J, et al (2019) Simultaneous recovery of microalgae, ammonium and phosphate from simulated wastewater by MgO modified diatomite. Chem Eng J 362:802-811.

14. Si Q, Zhu Q, Xing Z (2017) Designed and synthesis of a novel silicate material from red mud for simultaneous removal of nitrogen and phosphorus in waste water. Acs Sustain Chem Eng 5:1142211432

15. Wilfert P, Kumar PS, Korving L, et al (2015) The Relevance of Phosphorus and Iron Chemistry to the Recovery of Phosphorus from Wastewater: A Review. Environ Sci Technol 49:9400

16. Ajmal Z, Muhmood A, Usman M, et al (2018) Phosphate removal from aqueous solution using iron oxides: Adsorption, desorption and regeneration characteristics. J Colloid Interface Sci 528:145-155.

17. Wang Q, O'Hare D (2012) Recent Advances in the Synthesis and Application of Layered Double Hydroxide (LDH) Nanosheets. Chem Rev 112:4124-4155.

18. Zhao MQ, Qiang Z, Huang JQ, Fei W (2012) Hierarchical Nanocomposites Derived from Nanocarbons and Layered Double Hydroxides - Properties, Synthesis, and Applications. Adv Funct Mater 22:675694

19. Laipan M, Yu J, Zhu R, et al (2020) Functionalized layered double hydroxides for innovative applications. Mater Horizons.

20. Mandel K, Drenkova-Tuhtan A, Hutter F, et al (2013) Layered double hydroxide ion exchangers on superparamagnetic microparticles for recovery of phosphate from waste water

21. Kong L, Tian Y, Wang Y, et al (2019) Periclase-induced generation of flowerlike clay-based layered double hydroxides: A highly efficient phosphate scavenger and solid-phase fertilizer. Chem Eng $\mathrm{J}$ 359:902-913.

22. Yan H, Chen Q, Liu J, et al (2018) Phosphorus recovery through adsorption by layered double hydroxide nano-composites and transfer into a struvite-like fertilizer. Water Res 145:721-730.

23. Lu H, Zhu Z, Zhang H, et al (2016) Fenton-Like Catalysis and Oxidation/Adsorption Performances of Acetaminophen and Arsenic Pollutants in Water on a Multimetal Cu-Zn-Fe-LDH. ACS Appl Mater Interfaces 8:25343-25352

24. Drenkova-Tuhtan A, Schneider M, Mandel K, et al (2016) Influence of Cation Building Blocks of Metal Hydroxide Precipitates on their Adsorption and Desorption Capacity for Phosphate in Wastewater A Screening Study. Colloids Surf, A 488:145-153 
25. Di G, Zhu Z, Zhang H, et al (2017) Simultaneous removal of several pharmaceuticals and arsenic on Zn-Fe mixed metal oxides: Combination of photocatalysis and adsorption. Chem Eng J 328:141151.

26. Schneider M, Drenkova-Tuhtan A, Szczerba W, et al (2017) Nanostructured ZnFeZr Oxyhydroxide Precipitate as Efficient Phosphate Adsorber in Waste Water: Understanding the Role of Different Material-Building-Blocks. Environ Sci Nano 4:180

27. Zhang Q, Ji F, Zhao T, et al (2019) Systematic screening of layered double hydroxides for phosphate removal and mechanism insight. Appl Clay Sci 174:159-169.

28. Zhang X, Guo L, Huang H, et al (2016) Removal of phosphorus by the core-shell bio-ceramic/Znlayered double hydroxides (LDHs) composites for municipal wastewater treatment in constructed rapid infiltration system. Water Res 96:280-291.

29. Guaya D, Valderrama C, Farran A, Cortina JL (2017) Simultaneous nutrients (N,P) removal by using a hybrid inorganic sorbent impregnated with hydrated manganese oxide. J Environ Chem Eng 5:15161525

30. Thommes M, Smarsly B, Groenewolt M, et al (2006) Adsorption Hysteresis of Nitrogen and Argon in Pore Networks and Characterization of Novel Micro- and Mesoporous Silicas. 22:756-764

31. Yang F, Zhang S, Sun Y, et al (2019) Assembling biochar with various layered double hydroxides for enhancement of phosphorus recovery. J Hazard Mater 365:665-673.

32. Lu H, Zhu Z, Zhang H, et al (2015) Simultaneous removal of arsenate and antimonate in simulated and practical water samples by adsorption onto $\mathrm{Zn} / \mathrm{Fe}$ layered double hydroxide. Chem Eng $\mathrm{J}$ 276:365-375.

33. Ali O, Eduard D, Daniel A, Silvana A (2018) Nanoporous Sorbents for the Removal and Recovery of Phosphorus from Eutrophic Waters: Sustainability Challenges and Solutions. ACS Sustain Chem Eng 6:12542-12561

34. Fang L, Liu R, Li J, et al (2018) Magnetite/Lanthanum hydroxide for phosphate sequestration and recovery from lake and the attenuation effects of sediment particles. Water Res 130:243-254.

35. Szczerba W, Schneider M, Żukrowski J, et al (2017) Spectroscopic Study of the Role of Metal lons in the Adsorption Process of Phosphate in Nanoscaled Adsorbers Based on Metal (Zn/Fe/Zr) Oxyhydroxides. J Phys Chem C 121:25033-25042.

36. Yang S, Jin P, Wang X, et al (2016) Phosphate recovery through adsorption assisted precipitation using novel precipitation material developed from building waste: Behavior and mechanism. Chem Eng J 292:246-254.

37. Lin J, Zhan Y, Wang H, et al (2017) Effect of calcium ion on phosphate adsorption onto hydrous zirconium oxide. Chem Eng J 309:118-129.

38. Rashid M, Price NT, Gracia Pinilla MÁ, O'Shea KE (2017) Effective removal of phosphate from aqueous solution using humic acid coated magnetite nanoparticles. Water Res 123:353-360.

39. Tu Y-J, You C-F, Chang C-K, Chen M-H (2015) Application of magnetic nano-particles for phosphorus removal/recovery in aqueous solution. J Taiwan Inst Chem Eng 46:148-154. 
40. Deng Y, Weng L, Li Y, et al (2019) Understanding major NOM properties controlling its interactions with phosphorus and arsenic at goethite-water interface. Water Res 157:372-380.

41. Takaya CA, Fletcher LA, Singh S, et al (2016) Phosphate and ammonium sorption capacity of biochar and hydrochar from different wastes. Chemosphere 145:518-527.

42. Qiu X, Sasaki K, Xu S, Zhao J (2019) Double-Edged Effect of Humic Acid on Multiple Sorption Modes of Calcined Layered Double Hydroxides: Inhibition and Promotion. Langmuir 35:6267-6278.

43. Huang $H$, Yang $L$, Xue Q, et al (2015) Removal of ammonium from swine wastewater by zeolite combined with chlorination for regeneration. J Environ Manage 160:333-341.

44. Tarpeh WA, Udert KM, Nelson KL (2017) Comparing Ion Exchange Adsorbents for Nitrogen Recovery from Source-Separated Urine. Environ Sci Technol 51:2373-2381.

45. Mor S, Chhoden K, Ravindra K (2016) Application of agro-waste rice husk ash for the removal of phosphate from the wastewater. J Clean Prod 129:673-680.

46. Wan J, Wang R, Wang R, et al (2019) Comparative Physiological and Transcriptomic Analyses Reveal the Toxic Effects of ZnO Nanoparticles on Plant Growth. Environ Sci Technol 53:4235-4244.

47. Guaya D, Valderrama C, Farran A, et al (2015) Simultaneous phosphate and ammonium removal from aqueous solution by a hydrated aluminum oxide modified natural zeolite. Chem Eng $\mathrm{J}$ 271:204-213.

48. Cui Q, Jiao G, Zheng J, et al (2019) Synthesis of a novel magnetic Caragana korshinskii biochar/Mg-Al layered double hydroxide composite and its strong adsorption of phosphate in aqueous solutions. RSC Adv 9:18641-18651.

\section{Figures}



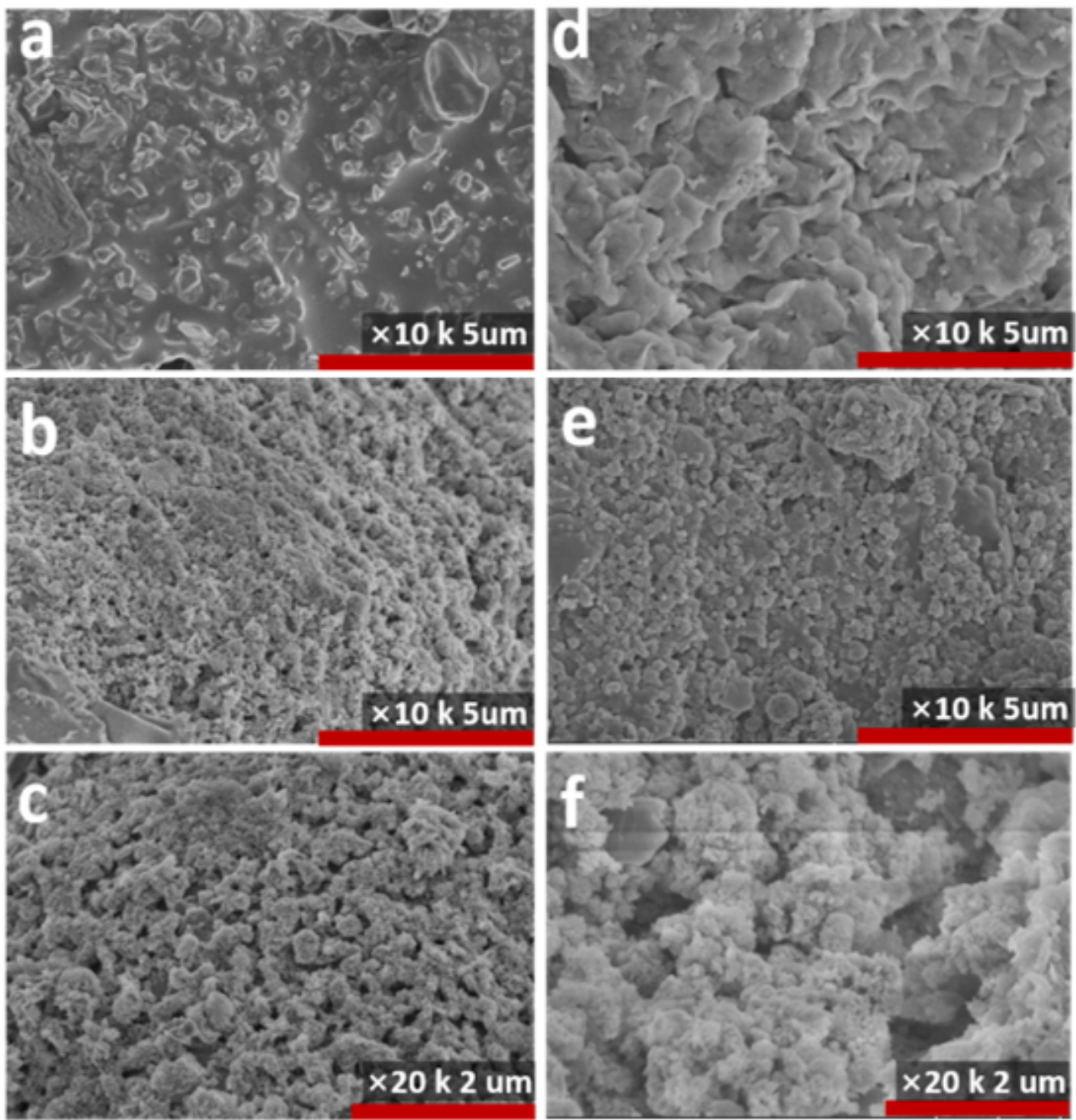

\section{Figure 1}

SEM micrographs of ceramsite (a), CZF (b-c), volcanic rock (d), and VZF (e-f). 


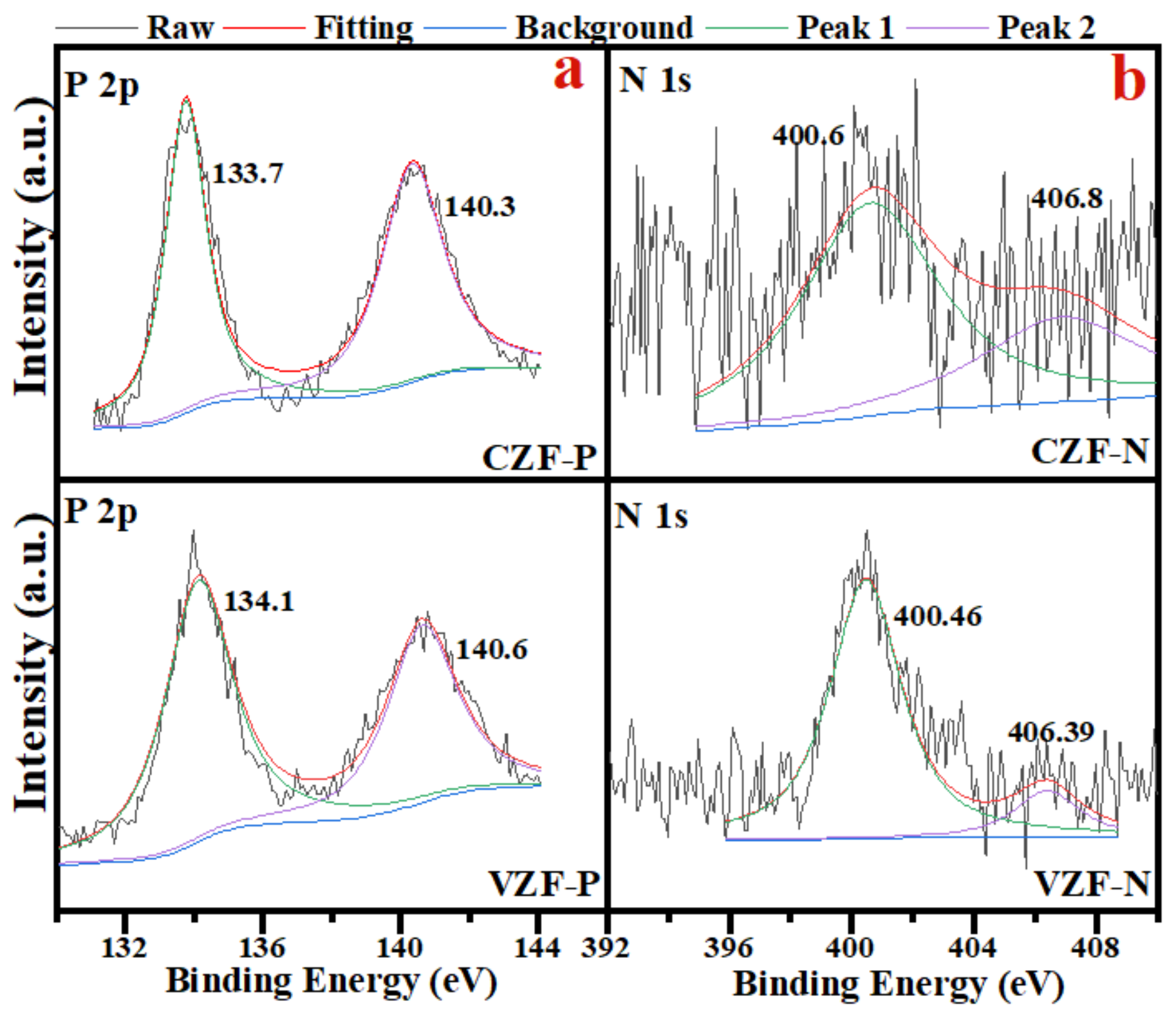

Figure 2

P 2p (a) and N 1s (b) regions of XPS spectra after adsorption. 


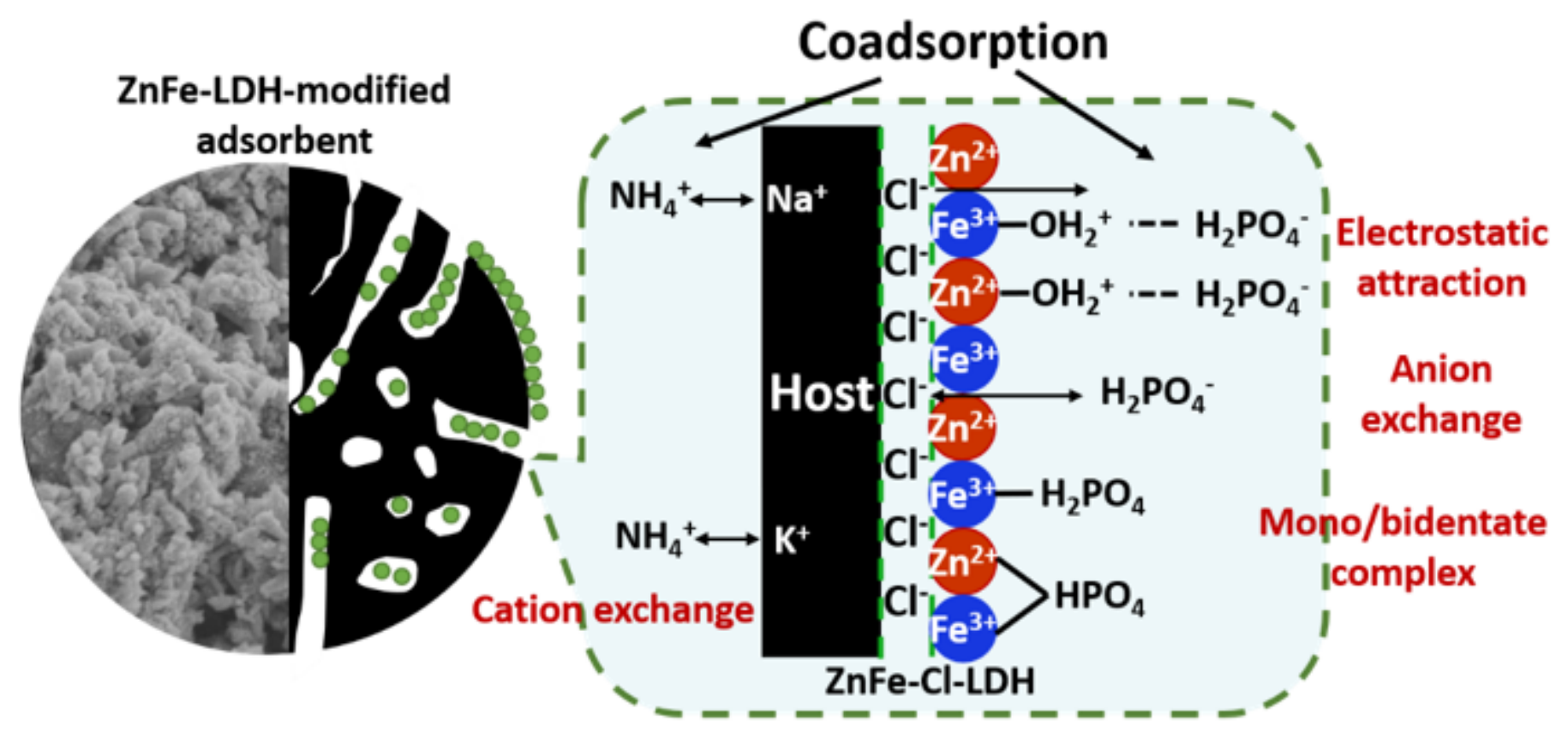

Figure 3

Schematic mechanism of simultaneous adsorption by ZnFe-LDH-modified adsorbent. 

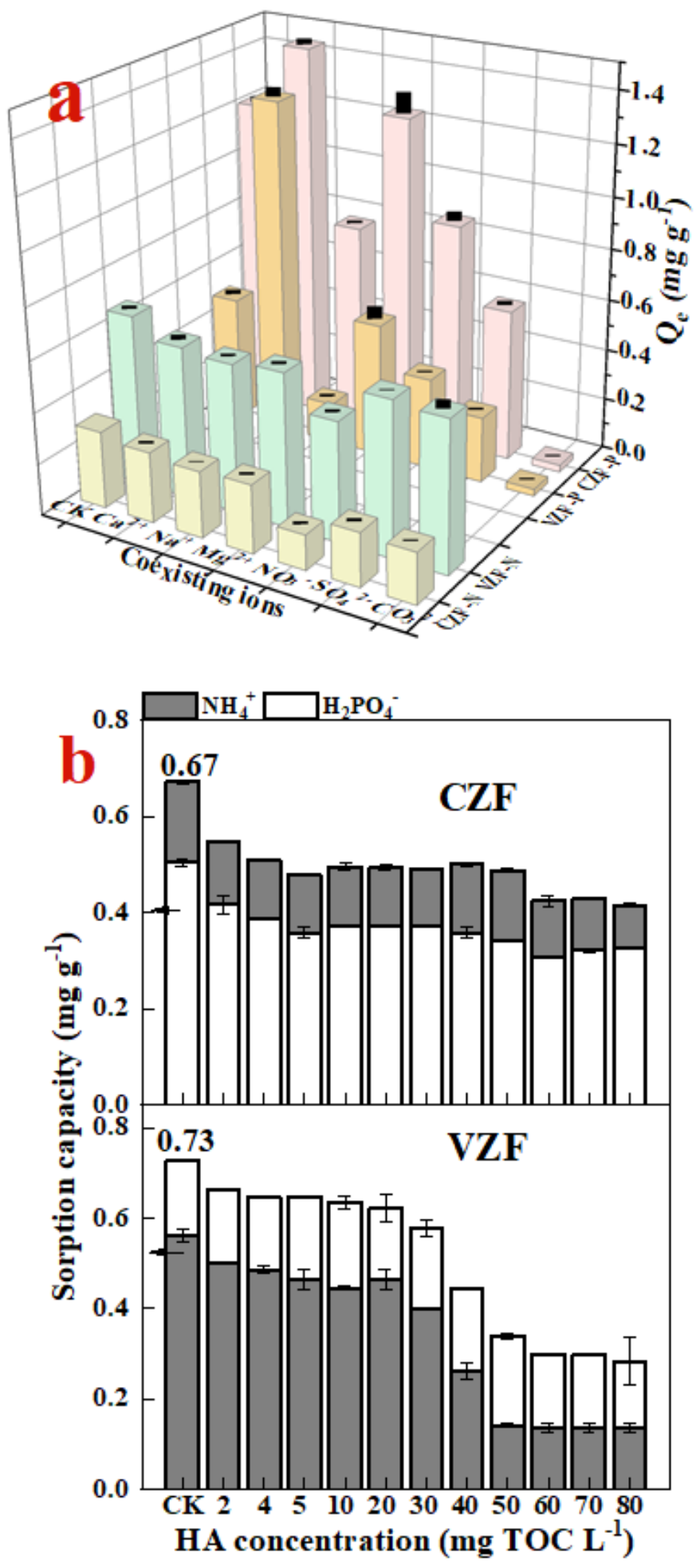

Figure 4

The effects of coexisting ions (a), and humic acid (b) on co-adsorption. 

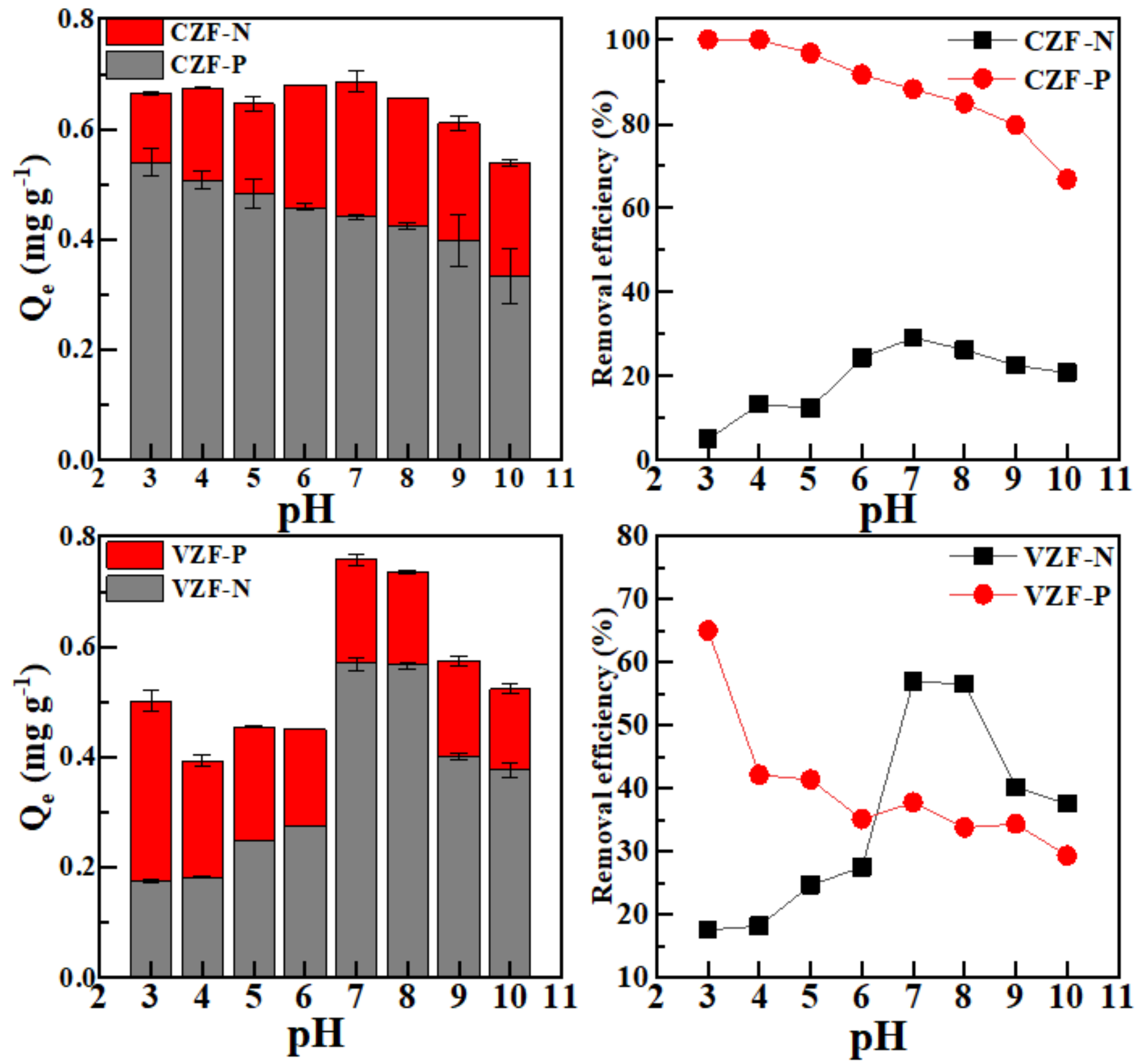

Figure 5

The effects of $\mathrm{pH}$ on co-adsorption by ZnFe-LDH-modified adsorbents. 

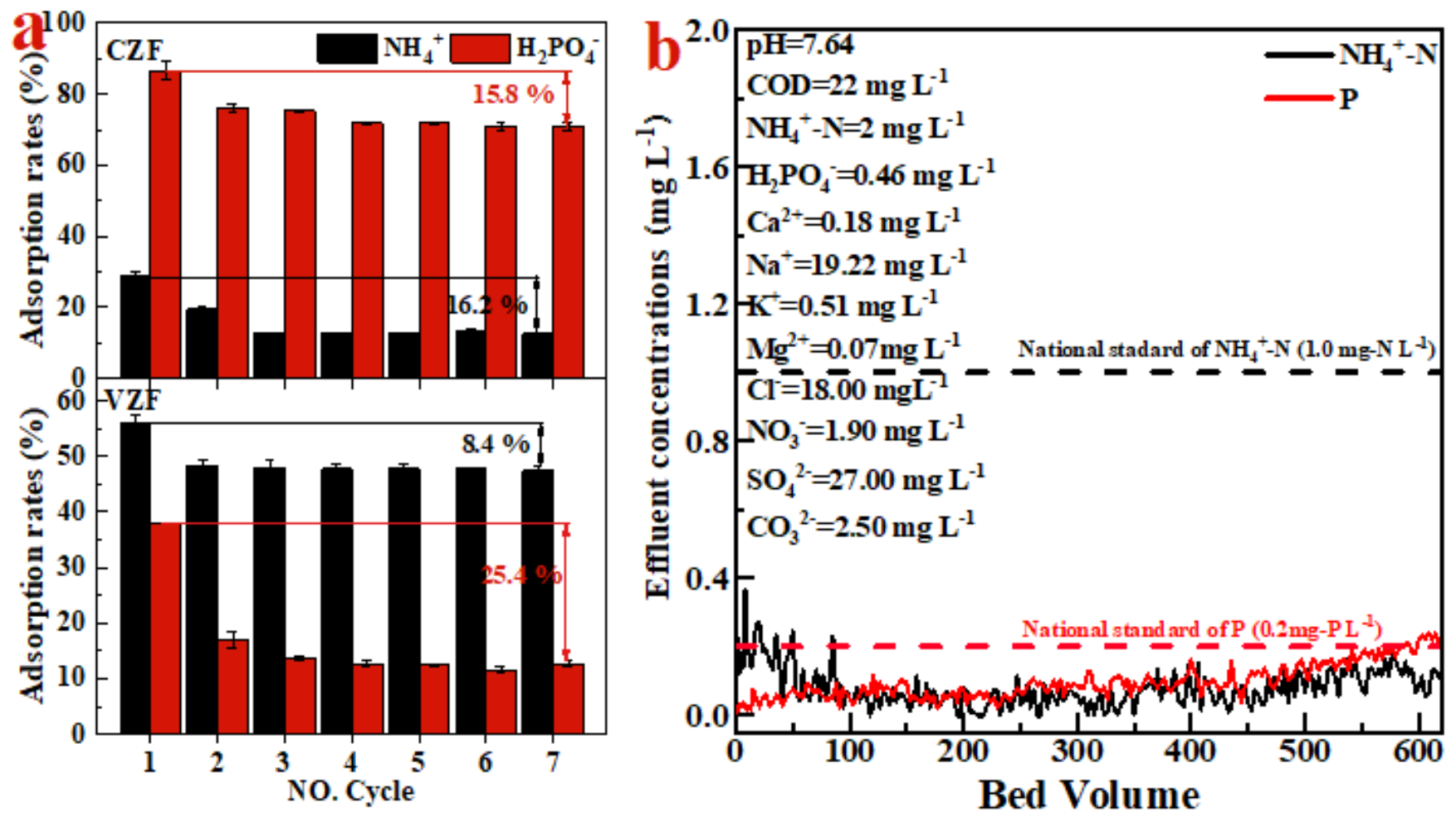

Figure 6

Seven adsorption cycles (a); breakthrough adsorption curves (b).

\section{Supplementary Files}

This is a list of supplementary files associated with this preprint. Click to download.

- Supplementarymaterial.docx 